\title{
Aplicação da Matriz de Leopold como ferramenta de avaliação dos aspectos e impactos ambientais em uma fábrica de botijões
}

\author{
Application of Leopold Matrix as an evaluation tool of environmental \\ aspects and impacts in a canisters factory
}

\author{
Leonardo Gondim \\ Cavalcante \\ leonardo_gondim@hotmail. \\ com \\ Universidade de Fortaleza

\section{Adriana de Oliveira Sousa \\ Leite \\ dricaoliver@unifor.br \\ Universidade de Fortaleza}

\begin{abstract}
Resumo
Este trabalho apresenta os resultados da avaliação ambiental do processo de fabricação de cilindros de armazenamento de gás liquefeito de petróleo (gás GLP) de uma indústria (fábrica de botijões) no Estado do Ceará. O método de avaliação utilizado foi a construção de matrizes de Leopold modificadas. Ela trabalha com o conceitos de interação entre ações do empreendimento e fatores ambientais, avaliando potenciais impactos ambientais potenciais, sendo analisadas questões referentes à significância, frequência, importância e criticidade de cada interação. A matriz contém em sua estrutura todas as atuações humanas relacionadas às atividades/etapas do processo de fabricação (eixo vertical), bem como os âmbitos físicos, biológicos e socioculturais, potencialmente afetados por estes processos (eixo horizontal). A geração de resíduos sólidos perigosos oriundos das atividades de fabricação de botijões são os aspectos ambientais que requerem maior atenção, sendo necessário o desenvolvimento de propostas de medidas de mitigação baseadas no princípio da tecnologia limpa.
\end{abstract}

Palavras-chave: Leopold Matrix. Aspectos ambientais Impactos ambientais. Medidas de mitigação.

\begin{abstract}
This paper presents the results of the environmental assessment of the manufacturing liquefied petroleum gas (LPG) storage cylinders oil process of an industry (canisters factory) of Ceará. The evaluation method used was the construction of modified "Leopold" arrays. This type of arrays works with concepts of interaction between actions of the project and environmental factors, generating potential environmental impacts, issues being analyzed regarding the significance, frequency, importance and criticality of each interaction. The matrix contains in its structure all human activities related to the actions / steps in the manufacturing process (vertical axis) as well as the physical, biological and socio-cultural aspects potentially affected by these processes (horizontal axis). The generation of hazardous solid waste from the cylinders manufacturing activities is the environmental aspects that require further attention are the main sources of impacts on water are soil, requiring the development of proposed mitigation measures based on the principle of clean technology.
\end{abstract}

Keywords: Mother of Leopold. Environmental aspects. Environmental impacts. Mitigation measures

\section{Introdução}

O Gás Liquefeito de Petróleo (GLP) surgiu no Brasil na década de 1930, quando os zepelins pararam de circular após o famoso desastre ocorrido com o dirigível Hindenburg, que pegou fogo no momento em que se preparava para descer em Nova Jersey, nos Estados Unidos, em 1937. O uso desse transporte ficou comprometido e o combustível usado foi proibido, levando ao acúmulo de grandes quantidades do gás propano. (IPEM, 2010). A distribuição de GLP no Brasil surgiu precisamente em 30 de agosto de 1937, quando um imigrante austríaco que há muitos anos estava radicado no país fundou, na cidade do Rio de Janeiro/RJ, a Empresa Brasileira de Gás a Domicílio Ltda., iniciando-se a venda de gás engarrafado. Foi então que Ernesto Igel comprou todos os cilindros e começou a comercializá-los como "gás de cozinha" (SINDIGAS, 2007). 
Os fabricantes de botijões são grandes consumidores de aço, seu principal material de fabricação; isso os caracteriza como causadores de impactos ambientais, provenientes da utilização de recursos naturais, além dos impactos causados durantetodo o processo produtivo. Atualmente, as empresas buscam alternativas para reduzi-los e atender às obrigações legais, utilizando sistemas de gestão ambiental, sobretudo integradas ao processo produtivo.

O consumo doméstico do GLP cresceu bastante ao longo da década de 1950, propiciando o surgimento de outras distribuidoras e fabricantes de botijões para atender à demanda. Um desses fabricantes, a Mangels, desenvolveu o projeto do botijão de $13 \mathrm{Kg}$, que acabaria se tornando o padrão brasileiro. Hoje, existem mais de 105 milhões de botijões em circulação em todo o país e, a cada dia, são entregues um milhão e quinhentos mil botijões aos consumidores brasileiros (SINDIGAS, 2007).

O GLP é um combustível de amplo emprego em atividades industriais, além de ser cotidianamente utilizado nas residências brasileiras.Conhecido como gás de cozinha, ele está presente em mais de $95 \%$ dos lares do país. Isso se deve, em parte, à segurança e praticidade que oferece a seus usuários: sob pressão moderada, o GLP assume o estado liquefeito, que facilita seu armazenamento e transporte; em caso de vazamento, assume o estado gasoso, porém, continua mais pesado que o ar, permanecendo próximo ao chão.

O Sistema de Gestão Ambiental (SGA) é um conjunto de procedimentos que irão ajudar uma dada organização a atender, controlar e diminuir os impactos ambientais de suas atividades, produtos e/ou serviços (AQUINO; ALMEIDA; ABREU, 2008). Uma das maneiras mais usuais de se iniciar uma gestão voltada para o meio ambiente tem sido a implantação do SGA, com vistas à certificação segundo as normas internacionais ISO 14000. O mais importante das normas da série ISO 14000 é o padrão de especificação do SGA - a ISO 14001se tornou uma importante ferramenta para as empresas demonstrarem a sua "preocupação" com o meio ambiente. Essa norma internacional caracteriza os elementos essenciais de um SGA e fornece uma estrutura para as organizações que buscam reduzir seus impactos ambientais, além de regulamentar os requisitos ISO 14001:2004.

Em virtude da adequação legal e ambiental, para diminuir os impactos, é necessário primeiramente identificar e avaliá-los. Isso é possível através de instrumentos de Avaliação de Impactos Ambientais (AIA), um processo sistemático de identificar, prever, avaliar e mitigar os efeitos relevantes de ordem biofísica, social ou outra de projetos ou atividades. Conforme Resolução CONAMA 01/86:01, impacto ambiental é definido como qualquer alteração das propriedades físicas, químicas e biológicas do meio ambiente causada por qualquer forma de matéria ou energia resultante das atividades humanas que direta ou indiretamente. Oartigo $6^{\circ}$ dessa resolução define que o EIA desenvolverá as seguintes atividades técnicas. Na Tabela 1, é mostrado um resumo das informações sobre definições de impactosambientais. Segundo a ISO 14001:2004, entende-se por aspecto ambiental um elemento componente das atividades, produtos ou serviços de uma organização que interage com o meio ambiente. Um aspecto ambiental significativo é aquele que tem ou pode ter um impacto ambiental significativo.

Tabela 1: Informações sobre definições de impacto ambientais.

\begin{tabular}{l|l}
\hline Pontos de afetados pelos impactos ambientais: & Atividades técnicas do EIA: \\
\hline I - a saúde, a segurança e o bem-estar da população; & I - diagnóstico ambiental da área de influência do projeto; \\
II - as atividades sociais e econômicas; & $\begin{array}{l}\text { II - análise dos impactos ambientais do projeto e de suas alternativas, } \\
\text { através de identificação, previsão da magnitude e interpretação da } \\
\text { III - a biota; }\end{array}$ \\
$\begin{array}{l}\text { IV - as condições estéticas e sanitárias do meio; } \\
\text { ambiente; e }\end{array}$ & $\begin{array}{l}\text { III - definição das medidas mitigadoras dos impactos negativos; } \\
\text { V - a qualidade dos recursos ambientais. }\end{array}$ \\
\hline
\end{tabular}

As matrizes de interações são técnicas bidimensionais que relacionam ações com fatores ambientais, embora possam incorporar parâmetros de avaliação, são métodos basicamente de identificação. Elas podem ser simples ou complexas, dependendo da quantidade de informações com que se trabalha (IBAMA, 2001).A interação entre os fatores dos eixos opostos permite estabelecer o impacto.

As matrizes tiveram início a partir da tentativa de suprir as deficiências das listagens (check-list). Uma das mais difundidas nacional e internacionalmente foi a Matriz de Leopold, criada por Leopold, em 1971, para o Serviço Geológico do Interior dos Estados Unidos. Trata-se de uma matriz bidimensional simples que relaciona as ações de um projeto a vários fatores ambientais (FOGLIATTI et al., 2004; MAVROULIDOU et al. 2007; SOUSA, 2011). 
Segundo Sánchez (2008), a Matriz de Leopold foi uma das primeiras ferramentas no formato de matriz feita para avaliar os impactos ambientais. A matriz é composta do cruzamento de 88 componentes (ou fatores) ambientais e 100 ações potencialmente alteradoras do ambiente, resultando em 8.800 quadrículas. Em cada uma dessas quadrículas são indicados algarismos que variam entre $1 \mathrm{e} \mathrm{10,} \mathrm{correspondendo,} \mathrm{respectivamente,} \mathrm{à} \mathrm{magnitude} \mathrm{e} \mathrm{à} \mathrm{importância} \mathrm{do} \mathrm{impacto.}$ Ao número 1 corresponde a condição de menor magnitude (mínimo da alteração ambiental potencial) e de menor importância (mínima significância da ação sobre o componente ambiental considerado). Ao número 10 correspondem os valores máximos desses atributos. O sinal (+) ou (-) na frente dos números indica se o impacto é, respectivamente, benéfico ou adverso. Como em outros métodos, existe o risco da subjetividade.

Conforme Leopold(1971), os impactos apresentam dois atributos principais: magnitude (grandeza em escala espaçotemporal da interação das ações) e importância (intensidade do efeito na área de influência do empreendimento ou fora dele, correspondente ao fator ambiental). "Magnitude é a medida extensiva, grau ou escala de impacto. Importância refere-se à significância da causa sobre o efeito." (RICHIERI, 2006).

O princípio básico da Matriz de Leopold consiste em, primeiramente, assinalar todas as possíveis interações entre as ações e os fatores, para em seguida ponderar a magnitude e a importância de cada impacto. Enquanto a valoração da magnitude é relativamente objetiva ou normativa, pois se refere ao grau de alteração provocado pela ação sobre o fato ambiental, a pontuação da importância é subjetiva ou empírica, uma vez que envolve atribuição de peso relativo ao fator afetado no âmbito do projeto (COSTA et al., 2005).

Porém, conforme apontamFogliattiet al. (2004), as vantagens desta ferramenta estão em permitir fácil compreensão dos resultados e abordar fatores biofísicos e sociais. Também permite utilizar poucos dados na sua elaboração, sendo eles qualitativos e quantitativos. Possui caráter multidisciplinar, baixo custo e simplicidade na elaboração, apresentando boa orientação e disposição visual.

\section{Metodologia}

Para atingir os objetivos propostos, o trabalho foi dividido nas seguintes etapas:

- realização do levantamento dos aspectos e impactos;

- definição da classificação dos impactos através da construção da planilha de aspectos eimpactos;

- quantificação dos impactos através da construção de Matrizes de Leopold;

- quantificação da geração de resíduos sólidos;

• identificação dos pontos prioritários para tomadas de ações.

O levantamento dos aspectos e impactos levou em consideração todos os materiais que entram e saem do processo do setor de pintura. Primeiramente, foi feito um estudo do processo do setor identificando todos os materiais e riscos ambientais. A metodologia da construção das planilhas de identificação permitiu elencar os aspectos ambientais da empresa, a partir do seu fluxograma de processo, determinando os impactos ambientais associados a estes aspectos e avaliar a sua importância, em termos de severidade, frequência e classificação. A planilha de identificação de aspectos e impactos ambientais foi preenchida em relação ao setor estudado observando-se os itens citados a seguir.

A Tabela 2apresenta informações para caracterizar o empreendimento que entram na elaboração da matriz. Com relação às avaliações pertinentes ao impacto em si, são adotados os critérios de severidade (classifica-se a gravidade do impacto causado ao meio ambiente) e frequência (define-se com qual frequência o impacto ocorre) conforme dados mostrados na Tabela3.

A classificação do impacto ambiental é definida através do cruzamento dos critérios de análiseseveridade e frequência/probabilidade, conforme Tabela4, fornecendo a categoria final no aspectoambiental em análise.Os fatores ambientais avaliados referem-se ao solo, à água e o ar. Uma adaptação para os objetivos deste estudo foi feita, com alterações relacionadas à pontuação do grau de importância, sendo consideradospontos que variam de 1 a 5 , e na matriz original variam de 1 a 10.A fim de facilitar a análise dos números obtidos, essas pontuaçõestambém estão apresentadas na Tabela4,como a importância do impacto. 
Tabela 2: Dados identificadores.

\begin{tabular}{l|l}
\hline Identificação & Itens \\
\hline Atividade & NA \\
\hline Componentes & $\begin{array}{l}\text { Aspecto ambiental - Elementos, atividades ou produtos que podem interagir com o meio ambiente. } \\
\text { Impacto ambiental - Qualquer modificação do meio ambiente, adversa ou benéfica, que resulte, no todo } \\
\text { ou em parte, das atividades, produtos ou serviços de uma organização. }\end{array}$ \\
\hline Situação do aspecto & $\begin{array}{l}\text { Normal (N) - Quando o aspecto é decorrente da atividade normal. } \\
\text { Anormal (A) - Quando o aspecto ocorreu em decorrência da realização de atividades de manutenção, } \\
\text { parada. } \\
\text { Emergencial (E) - Quando o aspecto ocorre em situações ou atividades não planejadas. }\end{array}$ \\
\hline Destino final & $\begin{array}{l}\text { Aterro sanitário (ATS) - Local de destinação dos resíduos que são caracterizados como classe II. } \\
\text { Estação de tratamento de efluentes (ETE) - Onde os efluentes gerados são tratados na própria fábrica. } \\
\text { Atmosfera (ATM) - Emissão atmosférica sem controle. } \\
\text { Coprocessamento (COP) - Fornos e coprocessamento, incineração. } \\
\text { Reciclador (REC) - Empresas recicladoras cadastradas pela empresa. } \\
\text { Logística reversa (LOG) - Logística reversa. } \\
\text { Não Aplicado (NA) - Atividade não geradora. }\end{array}$ \\
\hline
\end{tabular}

Tabela 3: Dados de avaliação do impacto ambiental identificado.

\begin{tabular}{l|l}
\hline Identificação & Itens \\
\hline Severidade do impacto & $\begin{array}{l}\text { Severidade baixa (B) - Abrangência local com potencial de magnitude desprezível. Degradação } \\
\text { ambiental sem consequências para o negócio e para a imagem da empresa, totalmente reversível com } \\
\text { ações de controle. } \\
\text { Severidade média (M) - Abrangência regional de média magnitude, capaz de alterar a qualidade } \\
\text { ambiental. Degradação ambiental com consequências para o negócio e à imagem da empresa, } \\
\text { reversíveis com ações de controle. } \\
\text { Severidade alta (A) - Abrangência global com potencial de grande magnitude. Degradação ambiental } \\
\text { com consequências financeiras e de imagem irreversíveis mesmo com ações de controle. }\end{array}$ \\
\hline $\begin{array}{l}\text { Frequência/Probabilidade } \\
\text { do impacto }\end{array}$ & $\begin{array}{l}\text { Frequência/Probabilidade baixa (B) - Ocorre raramente. Existência de procedimentos/controles/ } \\
\text { gerenciamentos adequados para os aspectos ambientais. Frequência/Probabilidade média (M) - } \\
\text { Ocorre mais de uma vez por mês. Existência de procedimentos/controles/gerenciamentos adequados } \\
\text { para os aspectos ambientais. } \\
\text { Frequência/Probabilidade alta (A) - Ocorre diariamente. Existência de procedimentos/controles/ } \\
\text { gerenciamentos adequados para os aspectos ambientais. }\end{array}$ \\
\hline
\end{tabular}

Tabela 4: Classificação e importância do impacto ambiental identificado.

\begin{tabular}{|c|c|c|c|c|}
\hline Identificação & \multicolumn{4}{|l|}{ Itens } \\
\hline \multirow[t]{5}{*}{ Classificação do impacto } & \multicolumn{4}{|c|}{$\begin{array}{l}\text { A classificação do impacto é definida através do cruzamento dos critérios de análise (Severidade x } \\
\text { Frequência/Probabilidade). }\end{array}$} \\
\hline & Impacto $\cdot \propto$ & ALTA $\propto$ & MÉDIA $\propto$ & BAIXA $\propto$ \\
\hline & ALTA $a$ & Alta-Significânciąa & Média-Significância: & Média-Significâncias \\
\hline & MÉDIA $\alpha$ & Média-Significânciaxa & Média-Significânciaxas & Baixa-Significânciąa \\
\hline & BAIXA $\alpha$ & Média-Significância:a & Baixa-Significânciax & Baixa-Significânciä: $=$ \\
\hline \multirow[t]{6}{*}{ A importância do impacto } & \multicolumn{4}{|c|}{$\begin{array}{l}\text { Ao número } 1 \text { corresponde a condição de menor importância (mínima significância da ação sobre } \\
\text { o componente ambiental considerado). Ao número } 5 \text { correspondem os valores máximos desses } \\
\text { atributos. }\end{array}$} \\
\hline & 1 & \multicolumn{2}{|c|}{ Baixo Impacto } & \\
\hline & 2 & \multicolumn{2}{|c|}{ Médio Baixo Impacto } & \\
\hline & 3 & \multicolumn{2}{|c|}{ Médio Impacto } & \\
\hline & 4 & \multicolumn{2}{|c|}{ Médio Alto Impacto } & \\
\hline & 5 & \multicolumn{2}{|c|}{ Alto Impacto } & \\
\hline
\end{tabular}


O totalizador é o somatório da pontuação quanto ao grau de criticidade de cada impacto. Somando todas as interações entre as linhas e colunas elaboradas na planilha, através do totalizador, podem-se visualizar os impactos com maior pontuação e maiores criticidades. Através dos dados do totalizador, é feito outro somatório para cada atividade do processo. Nesse somatório, é acrescentada, em todas as atividades, a etapa denominada "geral", que é imposta a todas as outras etapas do processo, resultando na ordenação do grau de importância das atividades.

\section{Resultados e discussão}

Após todo o mapeamento do processo produtivo e observação de cada etapa da atividade de fabricação do botijão, foi possível elencar os aspectos e os impactos ambientais envolvidos que irá dar subsídios à montagem da matriz. A Tabela 5 apresenta um quadro geral dos aspectos e impactos levantados na fabricação de botijões.

Tabela 5: Quadro geral dos aspectos e impactos levantados na fabricação de botijões.

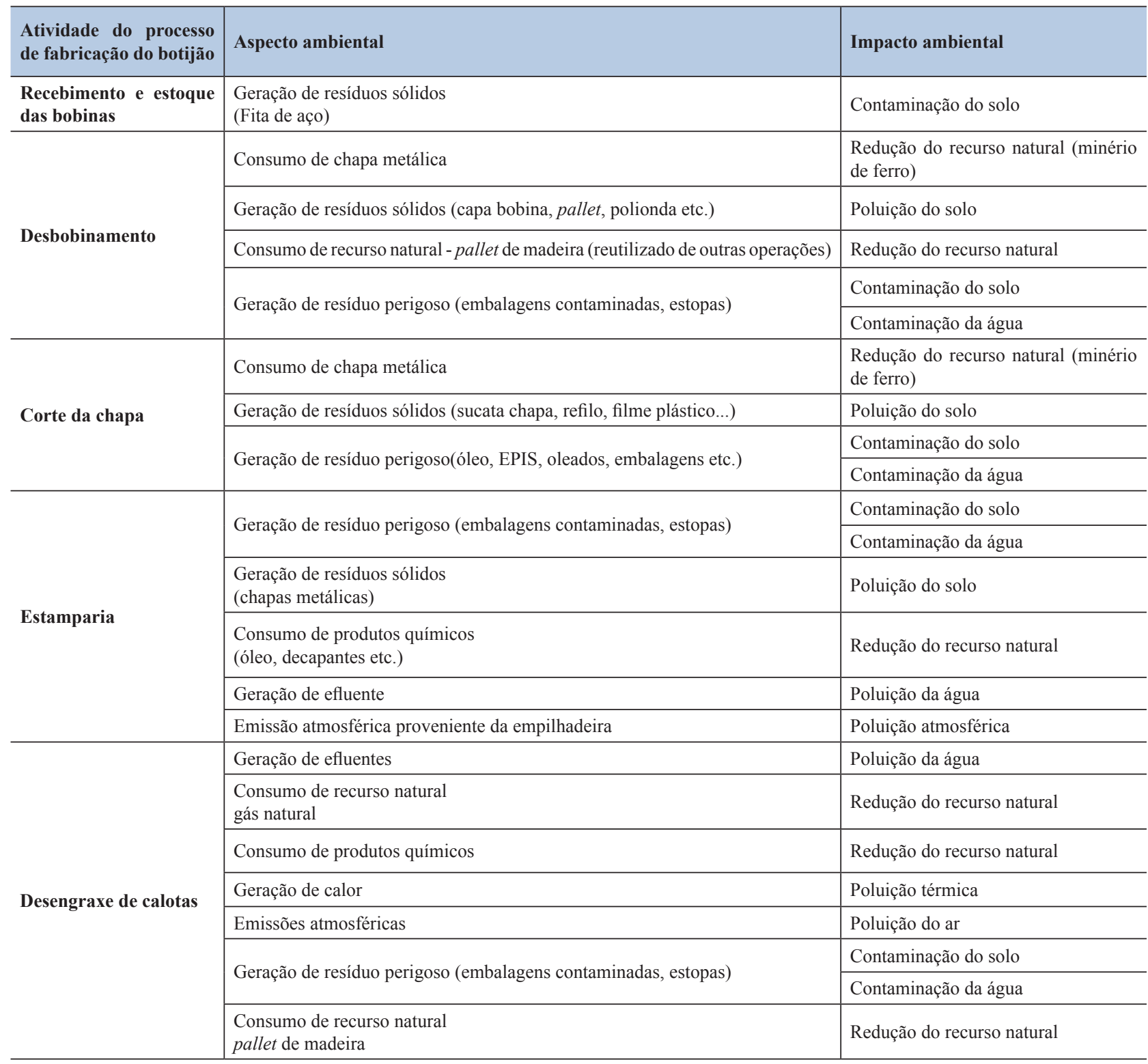




\begin{tabular}{|c|c|c|}
\hline $\begin{array}{l}\text { Atividade do } \\
\text { processo de } \\
\text { fabricação do botijão }\end{array}$ & Aspecto ambiental & Impacto ambiental \\
\hline \multirow{6}{*}{$\begin{array}{l}\text { Soldagem do flange/ } \\
\text { Base / Colarinho / } \\
\text { Circunferencial }\end{array}$} & Consumo de produtos químicos (arame, $\mathrm{CO}_{2}$, anti-respingo etc.) & Redução do recurso natural \\
\hline & $\begin{array}{l}\text { Emissões atmosféricas } \\
\text { fumos metálicos }\end{array}$ & Poluição do ar \\
\hline & Geração de calor & Poluição Térmica \\
\hline & Geração de resíduos sólidos (sobras metálicas etc.) & Contaminação do solo \\
\hline & \multirow{2}{*}{ Geração de resíduo perigoso (embalagens contaminadas, estopas) } & Contaminação do solo \\
\hline & & Contaminação da água \\
\hline \multirow{6}{*}{$\begin{array}{l}\text { Preparação da tinta } \\
\text { primer e acabamento } \\
\text { e aplicação de tinta }\end{array}$} & $\begin{array}{l}\text { Consumo de produtos químicos } \\
\text { (tintas, vernizes e solventes) }\end{array}$ & Redução do recurso natural \\
\hline & Emissões atmosféricas (VOCs) & Poluição do ar \\
\hline & \multirow{2}{*}{ Geração de resíduo perigoso (embalagens contaminadas, estopas) } & Contaminação do solo \\
\hline & & Contaminação da água \\
\hline & Risco de explosão & Poluição do ar \\
\hline & $\begin{array}{l}\text { Consumo de recurso natural } \\
\text { pallet de madeira }\end{array}$ & Redução do recurso natural \\
\hline \multirow{4}{*}{ Jateamento } & $\begin{array}{l}\text { Consumo de produto químico } \\
\text { (granalha de aço) }\end{array}$ & Redução do recurso natural \\
\hline & Emissões atmosféricas (VOCs) & Poluição do ar \\
\hline & \multirow{2}{*}{ Geração de resíduo perigoso (embalagens, granalha de aço). } & Contaminação do solo \\
\hline & & Contaminação da água \\
\hline Tratamento térmico & $\begin{array}{l}\text { Emissões atmosféricas } \\
\text { (gases de combustão) }\end{array}$ & Poluição do ar \\
\hline \multirow{3}{*}{$\begin{array}{l}\text { Colocação do plug e } \\
\text { da válvula }\end{array}$} & \multirow{3}{*}{$\begin{array}{l}\text { Geração de resíduo perigoso } \\
\text { (embalagens de cola) }\end{array}$} & Contaminação do solo \\
\hline & & Contaminação da água \\
\hline & & Contaminação da água \\
\hline \multirow{3}{*}{ Teste pneumático } & Geração de efluentes & Poluição da água \\
\hline & \multirow{2}{*}{$\begin{array}{l}\text { Geração de resíduo perigoso } \\
\text { (embalagens de cola) }\end{array}$} & Contaminação do solo \\
\hline & & Contaminação da água \\
\hline \multirow{7}{*}{ Geral } & Geração de varredura & Contaminação do solo \\
\hline & Geração de ruído & Poluição sonora \\
\hline & Incêndio por curto-circuito & Poluição do ar \\
\hline & Consumo de recurso natural - energia & Redução do recurso natural \\
\hline & Consumo de recurso natural - água & Redução do recurso natural \\
\hline & Geração de resíduos sólidos (plásticos, papelão etc.) & Contaminação do solo \\
\hline & Geração de resíduo perigoso (EPIS) & Contaminação do solo \\
\hline
\end{tabular}

Fonte: Elaborado pelos autores, 2014.

A fim de auxiliar um melhor entendimento e uma rápida compreensão, a matriz será apresentada de forma seccionada. Destacando cada fase do preenchimento de acordo com as percepções analisadas, no recorte (Figuras 1 e 2) a seguiré apresentado o formato da matriz. 
Figura 1: Detalhes da Matriz de Leopold.Fonte: Elaborado pelo autor, 2014.

MATRIZ DE LEOPOLD - AVALIAÇÃO DE IMPACTOS AMBIENTAIS

\begin{tabular}{|c|c|c|c|c|c|c|c|c|c|c|c|c|c|}
\hline \multirow[t]{2}{*}{ Fabrica de Botijão } & \multicolumn{2}{|l|}{ Componentes } & \multicolumn{2}{|c|}{ Situação } & \multirow{2}{*}{$\begin{array}{l}\text { Destino } \\
\text { Final }\end{array}$} & \multicolumn{7}{|c|}{ Impacto Ambiental } & Severidade requêncialassificaçã \\
\hline & & & N & $A E$ & & A $1 \mathrm{~N}$ & $M B$ & $A$ & M & $B$ & A & M & $B$ \\
\hline $\begin{array}{c}\text { Atividade do processo } \\
\text { de fabricação do } \\
\text { Botilaão } \\
\end{array}$ & Aspecto Ambiental & Impacto Ambiental & & & & & & & & & & & \\
\hline $\begin{array}{l}\text { Recebimento/armazena } \\
\text { mento das bobinas }\end{array}$ & Geração de resíduos sólidos (Fita de aço) & Contaminação do solo & N & & REC & & $X$ & & & $x$ & & & $X$ \\
\hline \multirow{3}{*}{ Desbobinamento } & Consumo de chapa metálica & $\begin{array}{l}\text { Redução do recurso natural } \\
\text { (minério de ferro) }\end{array}$ & N & & NA & & $x$ & & & $x$ & & & $X$ \\
\hline & Geração de resíduos sólidos (capa bobina, pallet, polionda, etc) & Poluição do solo & N & & REC & & $x$ & & & $x$ & & & $x$ \\
\hline & $\begin{array}{l}\text { Geração de resíduo perigoso (embalagens contaminadas, } \\
\text { estopas) }\end{array}$ & $\begin{array}{l}\text { Contaminação da água e do } \\
\text { solo }\end{array}$ & N & & COP & & $x$ & $x$ & & & & $X$ & \\
\hline
\end{tabular}

\section{Legenda:}

$\begin{array}{ll}\text { ATS } & \text { Aterro sanitário - ASMOC } \\ \text { ETE } & \text { Estação de tratamento de efluentes } \\ \text { ATM } & \text { Atmosfera - emissão atmosférica sem controle } \\ \text { COP } & \text { Coprocessamento - fornos e coprocessamentomincineração } \\ \text { REC } & \text { Reciclador-empresas recicladoras cadastradas pela empresa } \\ \text { LOG } & \text { Logísticareversa } \\ \text { NA } & \text { Não aplicado }\end{array}$

Figura 2: Continuação dos detalhes da Matriz de Leopold.

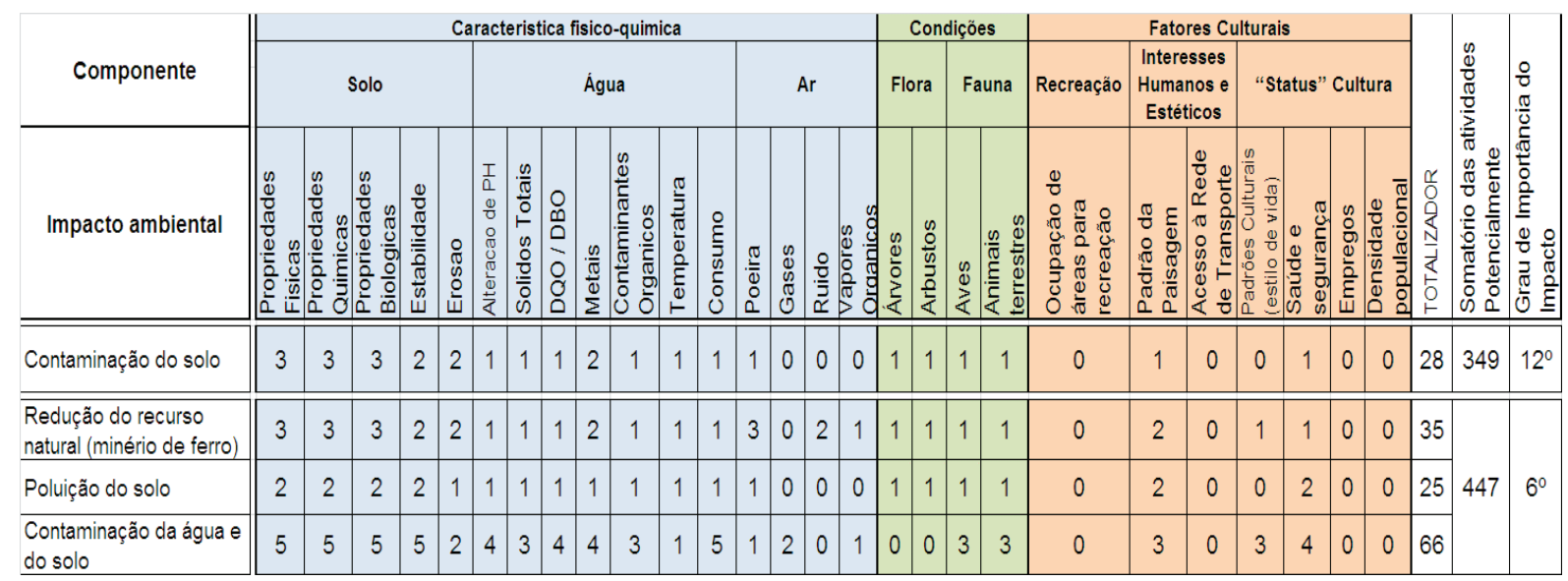

Fonte: Elaborado pelo autor, 2014.

Conforme é possível verificar na Tabela5, ao todo, foram evidenciadas 14 atividades, sendo acrescentada uma descrição denominada "geral". Essa descrição, "geral", conforme o recorte (Tabela 6) mostra os aspectos e impactos que são comuns a todas as 14 atividades do processo produtivo. A matriz do presente estudo foi composta pelo cruzamento de 27 componentes ambientais (colunas) e 48 ações potencialmente impactantes, resultando em um total de 1.296 quadrículas. 
Tabela 6: Detalhe dos aspectos e impactos para todas as atividades.

\begin{tabular}{l|l|l}
\hline $\begin{array}{l}\text { Atividade do processo } \\
\text { de fabricação do botijão }\end{array}$ & \multicolumn{1}{|c}{ Aspecto ambiental } & \multicolumn{1}{|c}{ Impacto ambiental } \\
\hline \multirow{4}{*}{ Geral } & Geração de varredura & Contaminação do solo \\
\cline { 2 - 3 } & Geração de Ruído & Poluição sonora \\
\cline { 2 - 3 } & Incêndio por curto-circuito & Poluição do ar \\
\cline { 2 - 3 } & Consumo de recurso natural - energia & Redução do recurso natural \\
\cline { 2 - 3 } & Consumo de recurso natural - água & Redução do recurso natural \\
\cline { 2 - 3 } & Geração de resíduos sólidos (plásticos, papelão etc.) & Contaminação do solo \\
\cline { 2 - 3 } & Geração de resíduo perigoso (EPIS) & Contaminação do solo \\
\cline { 2 - 3 } & $\begin{array}{l}\text { Derramamento/ vazamento de óleo / produtos } \\
\text { químicos }\end{array}$ & Contaminaçação do solo água \\
\cline { 2 - 3 } & Contaminação da água \\
\hline
\end{tabular}

Fonte: Elaborado pelo autor, 2014.

Ao todo, foi obtido um total de 48 impactos ambientais na referida fabricação de botijões; dentre estes, destacamos a seguinte correlação quanto à severidade dos impactos: $23 \%$ dos impactos são de alta severidade, $37 \%$ de média severidade e $40 \%$ de baixa severidade, conforme é visto no Gráfico 1a, na Figura 3. Continuando a análise da Matriz de Leopold do estudo em questão, o nível de frequência de ocorrência dos impactos teve as seguintes probabilidades: alta possibilidade de ocorrer totalizando $29 \%$, média frequência de ocorrer de $23 \%$ e baixa frequência, $58 \%$, conforme apresentado no Gráfico 1b.A classificação da significância do impacto é feita com o cruzamento dos dados de Severidade x Frequência/ Probabilidade, conforme mencionado na Tabela $1 ; 0$ resultado obtido confirma a inexistência de impactos de alta significância, e quanto aos de média significância, tivemos os valores de $52 \%$ e $48 \%$,relacionados à baixa significância. Esses dados estão demonstrados no Gráfico 1c e Tabela7.

O grau de criticidade foi feito conforme os dados da Tabela4, na qualé apresentada a pontuação para cada âmbito físico, biológico e sociocultural -, sendo correlacionado com os dados da classificação de significância de cada impacto, conforme o subtítulo anterior. A partir desse ponto, foi feito um somatório da pontuação e classificado o grau. Esse grau foi estabelecido de acordo com aquele que possui o maior somatório para o que possui menor somatório.

Figura 3: Análise geral dos critérios com relação aos impactos ambientais identificados.

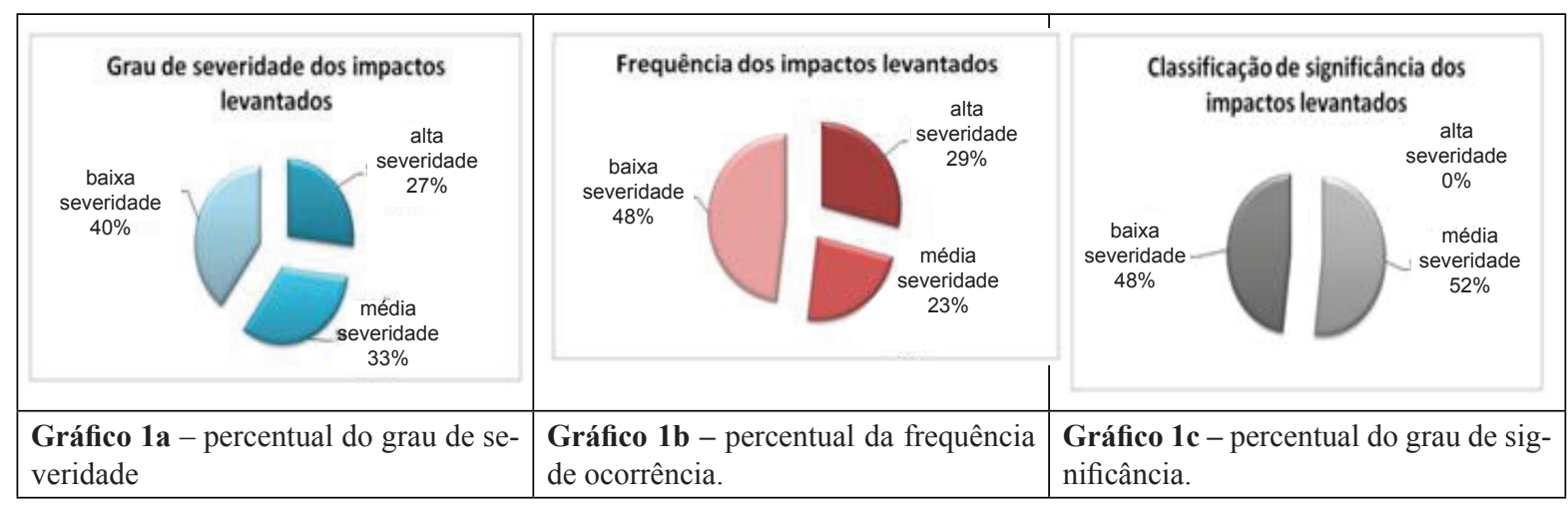


Tabela 7: Quadro dos impactos com o maior grau de criticidade.

\begin{tabular}{l|l|l|c}
\hline $\begin{array}{l}\text { Atividade do processo } \\
\text { de fabricação do botijão }\end{array}$ & \multicolumn{1}{|c|}{ Aspecto ambiental } & Impacto ambiental & TOTALIZADOR \\
\hline Pintura & $\begin{array}{l}\text { Geração de resíduo perigoso (embalagens } \\
\text { contaminadas, estopas) }\end{array}$ & $\begin{array}{l}\text { Contaminação da } \\
\text { água e do solo }\end{array}$ & 66 \\
\hline Pintura & Geração de resíduo perigoso (borra de tintas) & $\begin{array}{l}\text { Contaminação da } \\
\text { água e do solo }\end{array}$ & 66 \\
\hline Desengraxe de calotas & $\begin{array}{l}\text { Geração de resíduo perigoso (embalagens } \\
\text { contaminadas, estopas) }\end{array}$ & $\begin{array}{l}\text { Contaminação da } \\
\text { água e do solo }\end{array}$ & 66 \\
\hline $\begin{array}{l}\text { Solda (Flange / Base / } \\
\text { Colarinho circunferencial) }\end{array}$ & $\begin{array}{l}\text { Consumo de produtos quimicos (arame, CO } \\
\text { anti-respingo etc.) }\end{array}$ & $\begin{array}{l}\text { Redução do recurso } \\
\text { natural }\end{array}$ & 65 \\
\hline Estamparia & $\begin{array}{l}\text { Geração de resíduo perigoso (embalagens } \\
\text { contaminadas, estopas) }\end{array}$ & $\begin{array}{l}\text { Contaminação da } \\
\text { água e do solo }\end{array}$ & 64 \\
\hline Jateamento & $\begin{array}{l}\text { Geração de resíduo perigoso (embalagens, } \\
\text { granalha de aço) }\end{array}$ & $\begin{array}{l}\text { Contaminação da } \\
\text { água e do solo }\end{array}$ & 61 \\
\hline
\end{tabular}

Fonte: Elaborado pelo autor, 2014.

Diante do quadro geral, pode-se observar que os maiores valores foram 66 e 61, atribuídos aos impactos que causam contaminação da água e solo; já os menores valores foram 14 e 19, atribuídos aos impactos da poluição sonora e térmica, respectivamente. Na Tabela 7,são apresentados os impactos ambientais com os maiores graus de criticidade, ficando evidenciado que os impactos de maior grau são os que potencialmente contaminam a água e o solo, com a predominância dos aspectos que geram resíduos perigosos.

Todos os resultados podem ser vistos na Figura4, que mostra o quadro geral dos aspectos e impactos, já com o totalizador de cada impacto existente nas etapas do processo de fabricação dos botijões.

Dentre os demais impactos de maiores valores, é possível observar: o consumo de recurso natural (petróleo e minério de ferro), com 57 pontos, que retrata ao aspecto de consumo de produtos químicos (óleo, decapantes, anti-respingo, $\mathrm{CO}_{2}$, tintas, vernizes, solventes); depois, poluição da água com 54 pontos, que se refere ao aspecto geração de efluentes; redução de recurso natural (madeira), com 51 pontos, referente ao consumo de pallets de madeira; redução do recurso (gás natural), com 42 pontos, relacionada ao aspecto consumo do recurso natural; redução dos recursos naturais (água e energia), totalizando 39 pontos, relacionada ao grande consumo fabril; e alteração da qualidade do ar, com 39 a 36 pontos, proveniente de atividades que causam emissões atmosféricas. 
Figura 4: Quadro geral dos aspectos e impactos ambientais mostrando o grau de criticidade para cada impacto.

\begin{tabular}{|c|c|c|c|c|c|c|c|c|c|c|c|c|c|c|c|c|c|c|}
\hline \multirow{2}{*}{\multicolumn{2}{|c|}{ Fabrica de Botiaso }} & \multirow{3}{*}{$\begin{array}{c}\text { Componentes } \\
\text { Impacto ambiental }\end{array}$} & \multirow{2}{*}{\multicolumn{3}{|c|}{ sittuaçato }} & \multirow{3}{*}{$\begin{array}{l}\text { destino } \\
\text { final }\end{array}$} & \multirow{2}{*}{\multicolumn{9}{|c|}{ 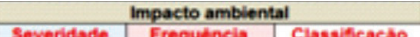 }} & \multirow{3}{*}{\begin{tabular}{|l} 
\\
\multirow{2}{*}{} \\
2 \\
3 \\
$\frac{3}{2}$ \\
$\frac{2}{5}$ \\
\end{tabular}} & \multirow{3}{*}{ 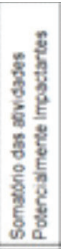 } & \multirow{3}{*}{ 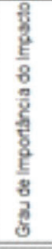 } \\
\hline & & & & & & & \multicolumn{2}{|c|}{ Severidade } & & & \multicolumn{2}{|c|}{ Frequineia } & \multicolumn{3}{|c|}{ Ciasuificaçato } & & & \\
\hline $\begin{array}{c}\text { Atividade do } \\
\text { processo de } \\
\text { fabricaçalo do } \\
\text { Botjato }\end{array}$ & Aspecto ambiental & & & & & & & & & & & & & & & & & \\
\hline $\begin{array}{l}\text { Recebimentolarmazo } \\
\text { namento das bobinas }\end{array}$ & $\begin{array}{l}\text { Gerasalo de residuos solidos } \\
\text { (Fla de aço) }\end{array}$ & Coreaminas, so do sols & N & & & REC & & & $x$ & & & $\mathrm{x}$ & & & $x$ & 28 & 349 & $12^{\circ}$ \\
\hline \multirow{3}{*}{ Denbobinamento } & Consumo de chapa metaica & 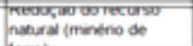 & $\mathrm{N}$ & & & MA & & & $x$ & & & $\mathrm{x}$ & & & $\mathrm{x}$ & 35 & \multirow{3}{*}{447} & \multirow{3}{*}{$6^{\circ}$} \\
\hline & $\begin{array}{l}\text { Gersajo de residuos sibjos } \\
\text { (capa bobina, pallet, polionda) }\end{array}$ & Poluecblo do selo & $N$ & & & REC & & & $x$ & & & $\mathrm{x}$ & & & $\mathrm{x}$ & 25 & & \\
\hline & $\begin{array}{l}\text { Gerasao de resido peryoso } \\
\text { (embalagens contaminadas. } \\
\text { estacus) }\end{array}$ & $\begin{array}{l}\text { Contaminazso da squa } \\
\text { edo solio }\end{array}$ & N & & & COP & & $x$ & & $\mathrm{x}$ & & & & $x$ & & 66 & & \\
\hline \multirow{3}{*}{ Corte da ehapa } & Consumo de chapa metaka & natural (mantina de & $\mathrm{N}$ & & & MA & & & $\mathrm{x}$ & & & $\mathrm{x}$ & & & $\mathrm{x}$ & 35 & \multirow{3}{*}{447} & \multirow{3}{*}{$7^{\circ}$} \\
\hline & 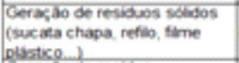 & Potursbo do selo & $\mathrm{N}$ & & & REC & & & $x$ & & & $\mathrm{x}$ & & & $\mathrm{x}$ & 25 & & \\
\hline & 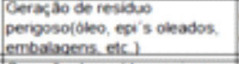 & $\begin{array}{l}\text { Conesminas to da doua } \\
\text { edo solio }\end{array}$ & $N$ & & & COP & & $\mathrm{x}$ & & $\mathrm{x}$ & & & & $x$ & & 66 & & \\
\hline & $\begin{array}{l}\text { Gerasao de residas pergoso } \\
\text { (embalagens contamnadas. } \\
\text { estapos) }\end{array}$ & $\begin{array}{l}\text { Contaminas do da sgua } \\
\text { edo solo }\end{array}$ & $\mathrm{N}$ & & & COP & & $\mathrm{x}$ & & $\mathrm{x}$ & & & & $\mathrm{x}$ & & 66 & & \\
\hline Estamparis & $\begin{array}{l}\text { Geras ato de resibues solugos } \\
\text { (ichapas metalca) }\end{array}$ & Potueças so secto & N & & & REC & & & $x$ & & & $x$ & & & $x$ & 28 & 492 & $4^{\circ}$ \\
\hline 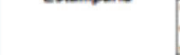 & $\begin{array}{l}\text { Consumo of producis } \\
\text { quimicos (dieo, decapantes, } \\
\text { efc) }\end{array}$ & $\begin{array}{l}\text { Redxy ao do recurso } \\
\text { natural }\end{array}$ & $\mathrm{N}$ & & & NA & & $\mathrm{x}$ & & & $\mathrm{x}$ & & & $\mathrm{x}$ & & 57 & 400 & 7 \\
\hline & $\begin{array}{l}\text { Emvssato amostenica } \\
\text { provenivente da empthasera }\end{array}$ & Potuçbo atmosterica & N & & & ATM & & $x$ & & & & $\mathrm{x}$ & & & $x$ & 20 & & \\
\hline & Gerasao de effurites & Poluec bo da bous & $\mathrm{N}$ & & & ETE & $\mathrm{x}$ & & & & $\mathrm{x}$ & & & $x$ & & 54 & & \\
\hline & $\begin{array}{l}\text { Consumo de recurso notural - } \\
\text { gas natural }\end{array}$ & $\begin{array}{l}\text { Reduxalo do recurso } \\
\text { nevaral }\end{array}$ & N & & & NA & & & $x$ & & & $x$ & & & $x$ & 42 & & \\
\hline & $\begin{array}{l}\text { Consume de produtios } \\
\text { quirices }\end{array}$ & $\begin{array}{l}\text { Redux } 30 \text { do recurso } \\
\text { nustiral }\end{array}$ & $N$ & & & NA & & $x$ & & & & $x$ & & & $x$ & 57 & & \\
\hline Desengraxe de & Geraça de calor & Potuçato Termica & $\mathrm{N}$ & & & MA & & & $\mathrm{x}$ & & & $\mathrm{x}$ & & & $\mathrm{x}$ & 19 & 630 & $2^{\circ}$ \\
\hline & Emissoes atmostericas & Polueçaso do a $x$ & $\mathrm{~N}$ & & & ATM & $\mathrm{x}$ & & & & $\mathrm{x}$ & & & $\mathrm{x}$ & & 20 & & \\
\hline & 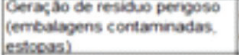 & $\begin{array}{l}\text { Conemminazso da soua } \\
\text { e } \infty 0 \text { sotio }\end{array}$ & $N$ & & & COP & & $x$ & & $\mathrm{x}$ & & & & $x$ & & 66 & & \\
\hline & $\begin{array}{l}\text { Consumo de recurso nstural - } \\
\text { pallet de madeira }\end{array}$ & $\begin{array}{l}\text { Reduxalo do recurso } \\
\text { nsturst }\end{array}$ & N & & & NA & & & $\mathrm{x}$ & & & $\mathrm{x}$ & & & $x$ & 51 & & \\
\hline & 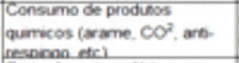 & $\begin{array}{l}\text { Redurato do recirso } \\
\text { natural }\end{array}$ & $\mathrm{N}$ & & & NA & & $\mathrm{x}$ & & & & $x$ & & & $x$ & 57 & & \\
\hline Solda (Flange / Base & $\begin{array}{l}\text { Emussoes atmostericas. } \\
\text { fumos metavicos }\end{array}$ & Poluecto do a & $N$ & & & ATM & $x$ & & & & $x$ & & & $x$ & & 36 & & \\
\hline | Colarinho & Geracalo de calor & Poluçso Termica & $N$ & & & NA & & & $x$ & & & $x$ & & & $x$ & 19 & 527 & $3^{\circ}$ \\
\hline & $\begin{array}{l}\text { Geracalo de revidios soldosos } \\
\text { (sobras mettacas, etc) }\end{array}$ & Cortsminac do do solo & $N$ & & & REC & & & $x$ & & & $\mathrm{x}$ & & & $x$ & 28 & & \\
\hline & $\begin{array}{l}\text { Ceras do de resida perigoso } \\
\text { (embalsgens contamnadas. } \\
\text { esacsas) }\end{array}$ & $\begin{array}{l}\text { Cortsminas do da spua } \\
\text { e do soto }\end{array}$ & $\mathrm{N}$ & & & COP & & $x$ & & $\mathrm{x}$ & & & & $x$ & & 66 & & \\
\hline & 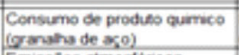 & $\begin{array}{l}\text { Redurato do recurso } \\
\text { nstural }\end{array}$ & $N$ & & & ATS & & $\mathrm{x}$ & & & $x$ & & & $x$ & & 32 & & \\
\hline Jatesmemio & $\begin{array}{l}\text { Emussoes atmostericas } \\
\text { (NoC's) }\end{array}$ & Polueçso do $\boldsymbol{\alpha}$ & $N$ & & & ATM & $\mathrm{x}$ & & & $\mathrm{x}$ & & & & $x$ & & 36 & 455 & $5^{\circ}$ \\
\hline & $\begin{array}{l}\text { Gerasdo de residxo perigoso } \\
\text { (embalagens, grmaha de } \\
\text { acol) }\end{array}$ & $\begin{array}{l}\text { Cortaminas do da dgua } \\
\text { e oo solio }\end{array}$ & $N$ & & & COP & & $x$ & & $x$ & & & & $x$ & & 66 & & \\
\hline & 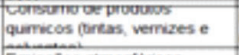 & $\begin{array}{l}\text { Redugato do recurso } \\
\text { natural }\end{array}$ & $N$ & & & NA & $x$ & & & & & $\mathrm{x}$ & & $\mathrm{x}$ & & 57 & & \\
\hline & $\begin{array}{l}\text { Emissós atmostericas } \\
\text { (VoC'S) }\end{array}$ & Polueçaso do a & $\mathrm{N}$ & & & ATM & $x$ & & & & $\mathrm{x}$ & & & $x$ & & 36 & & \\
\hline & 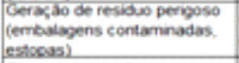 & $\begin{array}{l}\text { Cortaminas so da bgua } \\
\text { e do solio }\end{array}$ & $\mathrm{N}$ & & & COP & & $x$ & & $\mathrm{x}$ & & & & $\mathrm{x}$ & & 66 & & \\
\hline Pintura & Posco de explosto & Poluecbo do a & & & $\mathrm{N}$ & ATM & $\mathrm{x}$ & & & & & $x$ & & $x$ & & 39 & 690 & $1^{\circ}$ \\
\hline & $\begin{array}{l}\text { Consumo de recurso nstaral. } \\
\text { paltet de madeva }\end{array}$ & $\begin{array}{l}\text { Redusto do recurso } \\
\text { namaral }\end{array}$ & N & & & REC & & & $x$ & & $\mathrm{x}$ & & & & $x$ & 51 & & \\
\hline & Gerasalo de efluentes & Poluçbo da dous & $\mathrm{N}$ & & & ETE & $\mathrm{x}$ & & & & $\mathrm{x}$ & & & $\mathrm{x}$ & & 54 & & \\
\hline & $\begin{array}{l}\text { Gerasao de residio perigoso } \\
\text { (corra de trtas) }\end{array}$ & $\begin{array}{l}\text { Cortaminac do da soua } \\
\text { e do solio }\end{array}$ & $\mathrm{N}$ & & & COP & $x$ & & & $\mathrm{x}$ & & & & $\mathrm{x}$ & & 66 & & \\
\hline & Geras do de efluerties & Poluchbo da bous & $\mathrm{N}$ & & & ETE & $\mathrm{x}$ & & & & & $x$ & & & $x$ & 54 & & \\
\hline Teste pneumatico & $\begin{array}{l}\text { Gerasalo de residuo perngoso } \\
\text { (embalsyens de cola) }\end{array}$ & $\begin{array}{l}\text { Cortaminac do da doua } \\
\text { e do solo }\end{array}$ & $\mathrm{N}$ & & & COP & & $x$ & & $x$ & & & & $x$ & & 66 & 441 & $8^{\circ}$ \\
\hline & Geras ato de verredura & Cortaminas to do solo & $\mathrm{N}$ & & & ATS & & & $x$ & $x$ & & & & $x$ & & 33 & & \\
\hline & Ceras a do Ruido & Pokuçiso sonera & $\mathrm{N}$ & & & NA & & $\mathrm{x}$ & & $\mathrm{x}$ & & & & $\mathrm{x}$ & & 14 & & \\
\hline & Incelndo por sutos sirento & Polusçbo do a & & & $\mathrm{N}$ & ATM & $\mathrm{x}$ & & & & & $x$ & & $\mathrm{x}$ & & 39 & & \\
\hline & $\begin{array}{l}\text { Consumo de recurso nathar } \\
\text { eneras. }\end{array}$ & $\begin{array}{l}\text { Redus, a do recurso } \\
\text { natural }\end{array}$ & $N$ & & & NA & & & $x$ & & & $\mathrm{x}$ & & & $x$ & 39 & & \\
\hline Geral & $\begin{array}{l}\text { Consumo of recurso nowaral- } \\
\text { agus }\end{array}$ & $\begin{array}{l}\text { Redxato do recurso } \\
\text { netural }\end{array}$ & N & & & NA & & & $x$ & & & $x$ & & & $x$ & 39 & 321 & $13^{\circ}$ \\
\hline & 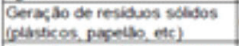 & Cortaminas, so do sols & $\mathrm{N}$ & & & REC & & & $x$ & & & $x$ & & & $x$ & 25 & & \\
\hline & $\begin{array}{l}\text { Ceracia de residos perigoso } \\
\text { (EPtS) }\end{array}$ & $\begin{array}{l}\text { Coreaminas do da sgua } \\
\text { edo solo }\end{array}$ & $N$ & & & COP & & $x$ & & $x$ & & & & $x$ & & 66 & & \\
\hline & $\begin{array}{l}\text { Derramamerto/ vaszamerto de } \\
\text { oleo i grodutos guimicos }\end{array}$ & $\begin{array}{l}\text { Cortarminas do da agua } \\
\text { e do solo }\end{array}$ & & & $N$ & COP & $x$ & & & & & $\mathrm{x}$ & & $x$ & & 66 & & \\
\hline
\end{tabular}

Fonte: Elaborado pelo autor, 2014. 
Aplicação da Matriz de Leopold como ferramenta de avaliação dos aspectos e impactos ambientais em uma fábrica de botijões

Com relação às atividades mais impactantes, é possível destacar que: a atividade considerada de maior impacto foi a etapa de pintura, devido às gerações de resíduos perigosos envolvidos nas embalagens e matéria-prima. A segunda maior atividade impactante, foi a etapa de desengraxe das calotas, devido à grande geração de efluente contaminado, consumo de produtos químicos e consumo do recurso natural água.

A Figura5 funciona como instrumento de informação para os gestores. Mostra em que se devem priorizar ações mitigadoras. É possível utilizar atividades com novas tecnologias para eliminar ou diminuir os impactos, porém, não é objetivo deste trabalho buscar processos alternativos, e sim propor meios que minimizem os impactos existentes em cada atividade atual, de acordo com seu grau de criticidade.

Figura 5: Priorização dos impactos ambientais do processo de fabricação de botijões.

\begin{tabular}{|c|c|c|c|c|c|}
\hline \multicolumn{2}{|c|}{ Fabrica de Botijāo } & \multicolumn{2}{|l|}{ Componentes } & \multirow{2}{*}{ 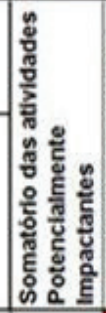 } & \multirow{2}{*}{ 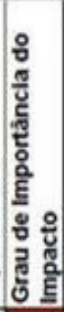 } \\
\hline 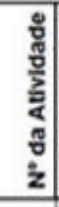 & $\begin{array}{c}\text { Atividade do } \\
\text { processo de } \\
\text { fabricaçăo do } \\
\text { Botijăo }\end{array}$ & Aspecto ambiental & Impacto ambiental & & \\
\hline \multirow{7}{*}{10} & \multirow{7}{*}{ Pintura } & Consumo de produtos quimicos (tintas, vernizes e solventes) & Reduçăo do recurso natural (petroleo) & \multirow{7}{*}{690} & \\
\hline & & Emissðes atmosféricas (VOC'S) & Alteraç১o da qualidade do ar & & \\
\hline & & Geraçこ̆o de residuo perigoso (embalagens contaminadas, estopas) & Contaminaçăo da água e do solo & & \\
\hline & & Risco de explosbo & Alteraçăo da qualidade do ar & & \\
\hline & & Consumo de recurso natural - pallet de madeira & Reduçðo do recurso natural (madeira) & & \\
\hline & & Geraçăo de efluentes & Polviç̧ăo da água & & \\
\hline & & Geraçăo de residuo perigoso (borra de tintas) & Contaminaçšo da água e do solo & & \\
\hline \multirow{7}{*}{5} & \multirow{7}{*}{$\begin{array}{c}\text { Desengraxe de } \\
\text { calotas }\end{array}$} & Geraçßó de efluentes & Poluiçð̄o da água & \multirow{7}{*}{630} & \multirow{7}{*}{$2^{\circ}$} \\
\hline & & Consumo de recurso natural - gás natural & Reduçšo do recurso natural & & \\
\hline & & Consumo de produtos quimicos & Reduçăo do recurso natural & & \\
\hline & & Geraçðo de calor & Poluiçào Térmica & & \\
\hline & & Emissðes atmostéricas & Alteraçbo da qualidade do ar & & \\
\hline & & Geraçăo de residuo perigoso (embalagens contaminadas, estopas) & Contaminação da água e do solo & & \\
\hline & & Consumo de recurso natural - pallet de madeira & Redução do recurso natural & & \\
\hline \multirow{5}{*}{6} & \multirow{5}{*}{$\begin{array}{c}\text { Solda (Flange I } \\
\text { Base I } \\
\text { Colarinho } \\
\text { Circunferencial) }\end{array}$} & Consumo de produtos quimicos (arame, $\mathrm{CO} 2$, anti-respingo) & Redução do recurso natural & \multirow{5}{*}{527} & \multirow{5}{*}{$3^{\circ}$} \\
\hline & & Emissð̄es atmosféricas - fumos metalicos & Alteraçấo da qualidade do ar & & \\
\hline & & Geraçầo de calor & Poluiçäo Térmica & & \\
\hline & & Geraçăo de residuos solidos (sobras metalicas, etc) & Contaminaçăo do solo & & \\
\hline & & Geraçðo de residuo perigoso (embalagens contaminadas, estopas) & Contaminaçふo da água e do solo & & \\
\hline \multirow{4}{*}{4} & \multirow{4}{*}{ Estamparia } & Geraçẫo de residuo perigoso (embalagens contaminadas, estopas) & Contaminaçăo da água e do solo & \multirow{4}{*}{492} & \multirow{4}{*}{$4^{0}$} \\
\hline & & Geraçåo de residuos solidos (chapas metalica) & Polviçăo do solo & & \\
\hline & & Consumo de produtos quimicos (oleo, decapantes, etc) & Reduçăo do recurso natural (petrobleo) & & \\
\hline & & Emissð̌o atmosférica proveniente da empilhadeira & Poluiç̧̋o atmosférica & & \\
\hline \multirow{3}{*}{9} & \multirow{3}{*}{ Jateamento } & Consumo de granalha de aço (esferas de aço) & $\begin{array}{l}\text { Reduçào do recurso natural (minério } \\
\text { de ferro) }\end{array}$ & \multirow{3}{*}{450} & \multirow{3}{*}{$5^{\circ}$} \\
\hline & & Emissð̄es atmostéricas (VOC'S) & Alteraç̋̀o da qualidade do ar & & \\
\hline & & Geraçăo de residuo solido ( granalha de aço) & Contaminaçăo da água e do solo & & \\
\hline
\end{tabular}

Fonte: Elaborado pelo autor, 2014. 
Conforme apresentado, a integração dos métodos de avaliação permite uma visualização rápida e hierarquizada dos impactos, além de permitir uma avaliação das medidas de controle adotadas.Esses resultados corroboram com as análises feitas em processo industrial de pintura no trabalho de Potrichet al. (2007), que conseguiu evidenciar e quantificar uma grande quantidade de resíduos, sendo a maior parte destes perigosos.

Conforme constatam Puczkó e Rátz (2000), as matrizes têm sido utilizadas em relatórios de impacto ambiental e, por vezes, em auditorias ambientais como um instrumento apto na indicação dos impactos atuais de determinadas atividades ou de projetos em proposição.No caso da fábrica de botijões, foi possível iniciar projetos de minimização dos impactos mais significativos.

As modificações realizadas na matriz original se fizeram necessárias para melhor caracterização, e esse fato foi observado no trabalho de Braz et al. (2015),que adaptaram sua Matriz de Análise Ambiental para Bacias Hidrográficas, passando de uma matriz de avaliação de impactos para uma matriz de identificação de alterações ambientais, provando ser eficaz na utilização em trabalhos de campo direcionados à análise e avaliação de bacias hidrográficas esendo passível de identificar as atividades impactantes e suas alterações no ambiente. A adaptação dessa matriz foi aplicada de forma satisfatória, assim como a deste trabalho,obtendo informações mais completas e integrativas das alterações identificadas no processo produtivo.

Através da Matriz de Leopold adaptada, foram identificados os cinco maiores impactos: contaminação da água e solo, redução do recurso natural (petróleo), redução do recurso natural (minério de ferro), redução do recurso natural (madeira) e poluição da água. Para as etapas em relação às atividades impactantes, destacamos que a etapa de pintura foi a mais importante, devido às gerações de resíduos perigosos envolvidos nas embalagens e matéria-prima. A etapa de desengraxe das calotas, com geração de efluente contaminado, consome de produtos químicos e recurso hídrico, as etapas de soldagem, estamparia e jateamento, respectivamente, compõem as demais atividades mais impactantes do processo fabril da fábrica de botijões.

\section{Conclusão}

A empresa em estudo, apesar de já possuir programas que buscam reduzir os impactos ambientais, como grupos de melhorias ambientais, monitoramento de emissões atmosféricas, inspeção veicular, plano de gerenciamento de resíduos sólidos, ainda não tinha o conhecimento dos maiores impactos da fábrica de botijões. A Matriz de Leopold permitiu o diagnóstico da situação atual, servindo como banco de dados para a elaboração de um plano de controle ambiental, criando prioridades a serem controladas e formulando diretrizes a serem seguidas.

A metodologia adotada propiciou a identificação e a avaliação dos aspectos e impactos ambientais da empresa, apontando como os mais significativos a geração de resíduos perigosos (EPIS, embalagens contaminadas, estopas, borra de tintas) e derramamento/vazamento de óleo/produto químico,caracterizados quanto à severidade das consequências diretas e indiretas que podem acarretar ao meio ambiente, quanto à frequência/probabilidade do impacto e quanto à criticidade do impacto.

Dentre as sugestões de redução aos referidos impactos ambientais, foram apresentadas como sugestões: higienização de EPIS como forma de reduzir o resíduo perigoso; manutenção preventiva, reduzindo os vazamentos de óleos; reaproveitamento da borra de tinta, propondo minimizar o resíduo perigoso e o consumo de recurso natural; novo destino para a granalha de aço, com o objetivo de reduzir a quantidade de resíduos sólidos encaminhados aos aterros; diminuição do consumo do recurso minério de ferro; e, por fim, implantação de uma logística reversa para embalagens contaminadas atendendo as exigências da Política Nacional dos Resíduos Sólidos.

A matriz aplicada no estudo ordenou de forma objetiva os principais impactos ambientais que são causados pela fábrica de botijões. É uma ferramenta que norteou as atividades mais impactantes, permitindo aos gestores uma visão ampla dos aspectos e impactos gerados. Esse instrumento torna-se indispensável para um setor de gestão ambiental, sendo utilizado para identificar onde devem ser implantadasuma proposta de mitigação ou até mesmo, se possível e viável, alterações de atividades no processo. A Matriz de Leopold pode ser aplicada a diversos setores da empresa, tanto aos que já existem como para processos futuros, e ainda em qualquer organização, necessitando apenas de adaptações para cada cenário. O sistema ambiental de posse desse mecanismo consegue traçar ou propor inúmeras situações de melhorias. 


\section{Referências}

AQUINO, A; ABREU, I; ALMEIDA, J. R (Orgs.). Análise de sistema de gestão ambiental: ISO 14000, ICC, EMAS. Rio de Janeiro: Thex, 2008.

ASSOCIAÇÃO BRASILEIRA DE NORMAS TÉCNICAS. NBR ISO 14001: sistema de gestão ambiental: requisitos com orientação para uso. 2. ed. Rio de Janeiro, 2004.

BRAZ, A. M; MIRANDOLA, P. H; COSTA, K. C. P. O. Uso da matriz ambiental como ferramenta de análise de alterações ambientais em trabalhos de campo: um estudo de caso na bacia hidrográfica do rio Carro Queimado - MSBRASIL. Rev. Conexão Eletrônica, v. 12, n.1, Três Lagoas, 2015.

BRASIL. Resolução CONAMA nº 001, de 23 de janeiro de 1986. Diário Oficial da União, Brasília, DF, 17 fev. 1986, p. 2548-2549.

COSTA, M. V.; CHAVES, P. S. V.; OLIVEIRA, F. C. Uso das Técnicas de Avaliação de Impacto Ambiental em Estudos Realizados no Ceará. In: XXVIII CONGRESSO BRASILEIRO DE CIÊNCIAS DA COMUNICAÇÃO, 28. 2005, Rio de janeiro. Anais... Rio de Janeiro: INTERCON, 2005.

FOGLIATTI, M. C.; FILIPPO, S.; GOUDARD, B. Avaliação de impactos ambientais: aplicação aos sistemas de transporte. Rio de Janeiro: Interciência, 2004.

Instituto Brasileiro do Meio Ambiente e dos Recursos Naturais Renováveis. Instrumentos de planejamento e gestão ambiental para a amazônia, cerrado e pantanal. Demandas e propostas: metodologias de avaliação de impacto ambiental - 37. Brasília: IBAMA, 2001.

Instituto de Pesos e Medidas de São Paulo. Almanaque do IPEM-SP. São Paulo, 2010. Disponível em: < http://ipemsp. wordpress.com/botijao-de-gas/ > Acesso em: 16 dez. 2014.

LEOPOLD, L. B. A procedure for evaluating environmental impact. Geological Survey Circular, Washington, n. 645, p. 1-16, 1971.

MAVROULIDOU, M.; HUGHES, S. J.; HELLAWELL, E. E. Developing the interaction matrix technique as a tool assessing the impact of traffic on air quality. Journal of Environmental Management, n. 84, p. 513-522, 2007.

POTRICH, A. L.; TEIXEIRA, C. E.; FINOTTI, A. R. Avaliação de impactos ambientais como ferramenta de gestão ambiental aplicada aos resíduos sólidos do setor de pintura de uma indústria automotiva. Estudos Tecnológicos em Engenharia, n. 3, v. 3, p. 168-175, out./dez. 2007.

PUCZKÓ, L.; RÁTZ, T. Tourism and resident perceptions of the physical impacts of tourism at lake Balaton, Hungary: issues for sustainable tourism management. Journal of Sustainable Tourism. U.K., v. 8, n. 6, p. 458-478, 2000.

RICHIERI, S. M. M. Estudo do impacto das mudanças climáticas globais nos mangues tropicais. 2006. $117 \mathrm{f}$. Dissertação (Mestrado em Engenharia de Processos Químicos e Bioquímicos) - Escola de Engenharia Mauá, São Caetano do Sul, 2006.

SÁNCHEZ, L. E. Avaliação de impacto ambiental: conceitos e métodos. São Paulo: Oficina de Textos, 2008.

SINDIGÁS. Sindicato nacional das empresas distribuidoras de gás liquefeito de petróleo. Fevereiro, 2007.

SOUSA, R. N. A simplified matrix of environmental impacts to support an intervention program in a small-scale mining site. Journal of Cleaner Production, v. 19, p. 580-587, 2011. 


\section{Leonardo Gondim Cavalcante}

Engenheiro Ambiental e Sanitário pela UNIFOR em 2014. Atualmente trabalha em Geoconsult LTDA, como Analista Ambiental II no Complexo Eólico Caldeirão Grande do Piauí. Experiência em monitoramento ambiental em Complexo Eólico, gestão de equipe, aplicação de programas ambientais exigidos em Estudo de Impacto Ambiental durante a fase de construção da obra, de forma a atender as condicionantes solicitadas em Licença Ambiental. Atuação em impactos Ambientais gerados em processos de fabricação de eletrodomésticos da "linha branca".

\section{Adriana de Oliveira Sousa Leite}

Graduada em Química Industrial pela Universidade Federal do Ceará (1994), mestrado (1999) e doutorado (2004) em Química Inorgânica pela UFC. Profissional Green Belt pela Fa7 em 2014. Especialista em processos químicos (tratamento de superfície, pintura, esmaltação). Experiência em sistema de gerenciamento da qualidade e de produção, coordenação de produção em setores como fundição de não metais, pintura industrial, esmaltação e moinhos. Coordenação de laboratórios de controle de produção e desenvolvimento. 